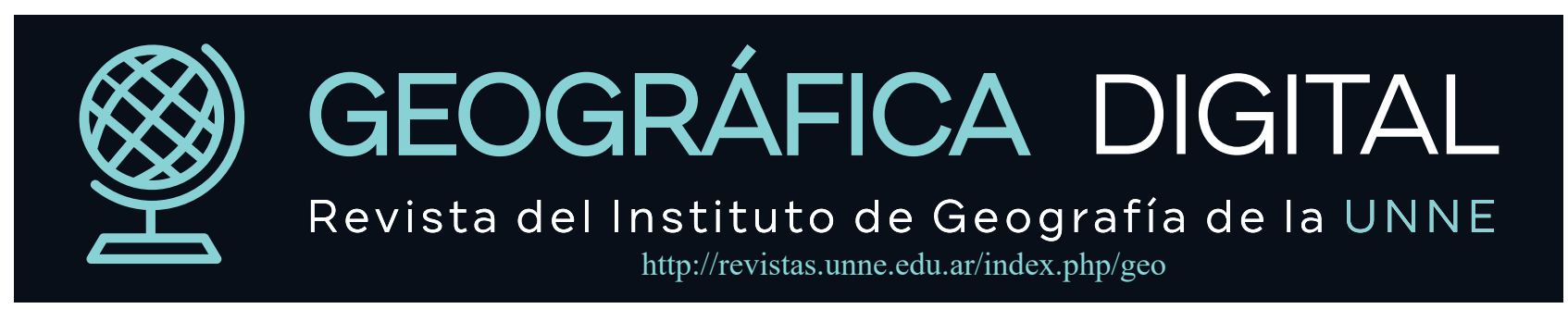

Revista Geográfica Digital, 2021, Vol. 18, No 35, 2-17 pp., E-ISSN: 1668-5180: DOI: http://dx.doi.org/10.30972/geo.18355136

\title{
Modificaciones en el ámbito productivo rural de Quitilipi
}

\author{
Modifications in the rural productive environment of Quitilipi
}

\section{Martínez, Gerardo R.}

Agencia de Extensión Rural INTA San Martín (Chaco). Instituto de Geografía - Facultad de Humanidades (UNNE). martinez.gerardo@inta.gob.ar

\begin{abstract}
R E S U M E N
Palabras Claves:

Transformaciones territoriales Departamento Quitilipi Desarrollo productivo Evolución poblacional Estructura productiva agropecuaria

El departamento chaqueño de Quitilipi ha tenido a lo largo del tiempo transformaciones en su estructura poblacional, parcelaria y productiva, condicionadas por factores políticos, económicos, climáticos y biológicos que han dado lugar a la actual configuración territorial. Se analiza en el artículo el proceso vivido en este departamento desde su creación en 1954, donde luego de un inicio forestal, seguido por la introducción y consolidación del cultivo de algodón que dio lugar a la formación de pueblos y colonias que, bajo el amparo de la legislación vigente, dio lugar a la conformación de la actual estructura de tenencia de la tierra.

Las crisis algodoneras obligaron a los productores a buscar alternativas para continuar resistiendo en el medio rural; aquellos que lo lograron fue merced a la actividad ganadera y la diversificación agrícola en un primer momento, a la revalorización de la actividad forestal, con su transformación en el territorio y a la comercialización local de productos tradicionalmente destinados al autoconsumo en otro momento histórico.
\end{abstract}

\section{A B S T R A C T}

The Chaco department of Quitilipi has undergone transformations over time in its population, parcel and productive structure, conditioned by political, economic, climatic and biological factors that have given rise to the current territorial configuration. The article analyzes the process experienced in this department since its creation in 1954, where after a forestry start, followed by the introduction and consolidation of cotton cultivation that gave rise to the formation of towns and colonies that, under the protection of the current legislation gave rise to the conformation of the current land tenure structure.

The cotton crises forced the producers to look for alternatives to continue resisting in rural areas; those that achieved it were thanks to livestock activity and agricultural diversification at first, to the revaluation of forestry activity, with its transformation in the territory and to the local commercialization of products traditionally destined for self-consumption in another historical moment. 


\section{Introducción}

El presente que vive una sociedad es fruto de muchos pasados, la historia no está predeterminada ni el presente es fruto de un determinismo histórico que marca que lo que hoy se es, es porque así debía ser. El territorio es el fruto de realizaciones humanas, de la lucha de clases, de la confrontación con la naturaleza a la cual se la ha querido dominar en lugar de colaborar con ella para vivir mejor; por lo tanto, el territorio no es un simple espacio físico, sino un espacio geográfico con características particulares, un sistema dinámico complejo, en construcción, con componentes biofísicos y sociales en relaciones de colaboración / conflicto donde se realiza un proceso de territorialización, tanto simbólica como funcional. Con esta mirada, se comprende que en cada espacio geográfico se vayan produciendo transformaciones, con distintas velocidades según el contexto histórico en el cual se desarrollan.

En el presente artículo se analiza el proceso de territorialización ocurrido en el departamento Quitilipi, ubicado en el centro oriental de la provincia del Chaco, con una mirada orientada a los procesos productivos agropecuarios. La superficie que hoy ocupa el denominado departamento Quitilipi fue incorporado formalmente al Territorio Nacional del Chaco recién en 1904, cuando fue incluido en el departamento VI-Caaguazú; este territorio nacional fue provincializado a través de la ley № 14.037, sancionada el 8 de agosto de 1951. Tres años más tarde, por la ley № 6/1954, se crearon los 24 departamentos ${ }^{1}$ en los cuales se dividió la novel provincia del Chaco, entre ellos Quitilipi, con su actual conformación.

En el proceso de construcción territorial intervinieron e intervienen grupos dominantes y grupos subalternos y, como figura siempre presente, la "mano visible" del Estado, facilitando, promoviendo, intentando regular la territorialidad que se va construyendo, favoreciendo a determinados sectores en perjuicio de otros (Martínez, 2018).

\section{Antecedentes}

No abundan los trabajos sobre la evolución territorial en los departamentos chaqueños; sobre distintas temáticas donde aparece relacionado el departamento Quitilipi pueden citarse trabajos de Mari $(2001$; 2016) sobre la seguridad de la población radicada en el territorio chaqueño y los procesos inmigratorios ocurridos en la primera mitad del siglo XX, Beck (1994) sobre las relaciones entre nuevos pobladores y pueblos originarios, Codutti (2003) realiza un diagnostico rural de la provincia del Chaco y, específicamente sobre el sector rural de Quitilipi, una propuesta de lineamientos de estrategias para el desarrollo rural del departamento elaborado por CEPRODER (2006).

\section{Materiales y metodos}

Para la realización del presente trabajo se recurrió al ya mencionado diagnóstico del sector rural de Quitilipi (CEPRODER, 2006), a información bibliográfica, artículos científicos y periodísticos, documentos publicados y estadísticas oficiales. En su tarea profesional, el autor ha realizado numerosas salidas de campo, obteniéndose documentos primarios resultantes de observaciones y entrevistas abiertas a actores territoriales, recopilando información que surgía de las conversaciones mantenidas con familias rurales en función de la actividad laboral que se desarrollaba; el relato de antiguos pobladores suministró la comprensión de hechos y procesos, enriqueciendo el trabajo y otorgándole significación a la trama geohistórica que se aborda. El trabajo fue desarrollado desde el paradigma interpretativo sociohistórico, específicamente desde la perspectiva de la geografía histórica, intentando aportar al conocimiento del territorio, sobre el que existen pocos trabajos que aborden la dinámica poblacional y productiva.

El estudio se centra en el departamento chaqueño de Quitilipi y analiza las transformaciones ocurridas en el ámbito productivo rural, desde su creación en 1954 -pocos años antes del inicio de la primera gran crisis algodonera ocurrido hacia finales de la década de 1950, inicios de 1960-, pasando por las transformaciones acaecidas hacia finales del siglo XX y las dos primeras décadas del XXI con la mecanización del cultivo y la aparición del picudo del algodonero (Anthonomus grandis Boheman).

$1 \quad$ Por Ley provincial 3.814 del 9 de diciembre de 1992, se creó en el sudoeste provincial el departamento Dos de Abril, con tierras de los departamentos Doce de Octubre y Fray Justo Santa María de Oro, configurando la actual división de 25 departamentos. 


\section{Resultados}

\subsection{Ubicación}

El departamento Quitilipi posee una superficie de $1.545 \mathrm{~km}^{2}$, ubicándose en el centro este de la provincia del Chaco, lindando al norte con el departamento Libertador General San Martín, al oeste con los departamentos Comandante Fernández y Maipú, al este con el departamento 25 de Mayo y al sur con el departamento San Lorenzo. La ciudad cabecera, del mismo nombre, dista $148 \mathrm{~km}$ de Resistencia, capital de la provincia, y $25 \mathrm{~km}$ de Presidencia Roque Sáenz Peña, segunda ciudad provincial, con quienes se comunica a través de la Ruta Nacional $\mathrm{N}^{\circ} 16$ Don Anselmo Zoilo Ducca, que atraviesa el departamento de este a oeste en sentido paralelo a las vías pertenecientes al Ferrocarril General Belgrano (trocha de 1.000 $\mathrm{mm}$ ); la Ruta Provincial № 4, que pasa al oeste de la ciudad de Quitilipi, atraviesa el departamento en sentido norte-sur, vinculándolo al sur con Villa Berthet y al norte con Pampa del Indio.

Figura 1. Ubicación del departamento Quitilipi.

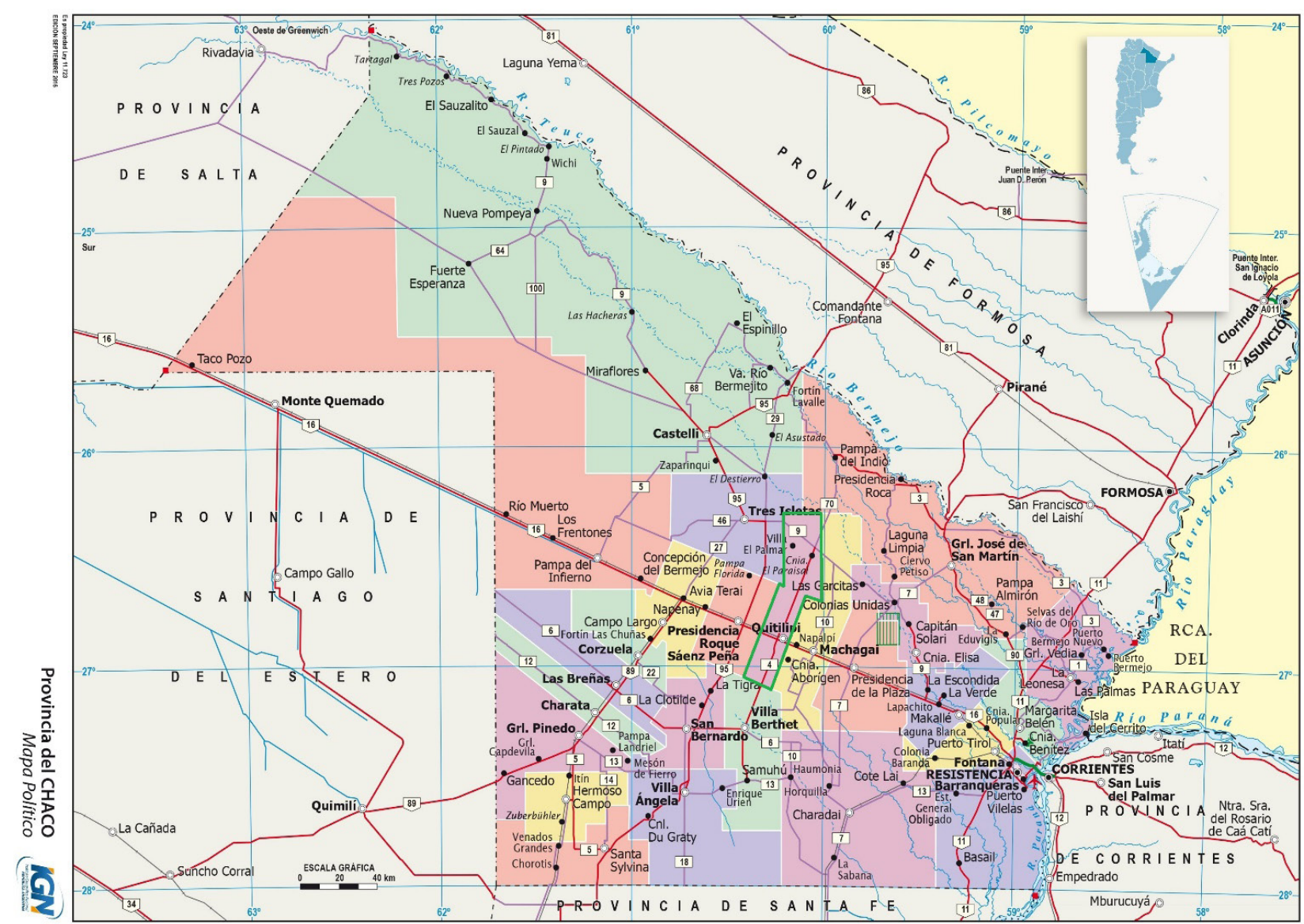

Fuente: elaboración propia en base a (República Argentina - Instituto Geográfico Nacional, 2016).

Este departamento alberga al municipio de Quitilipi, siendo esta ciudad cabecera departamental y sede del gobierno municipal; este es un municipio de primera categoría, donde el poder ejecutivo se encuentra a cargo del Intendente Municipal y el Poder Legislativo a cargo de un Concejo Deliberante constituido por nueve miembros. El 26 de agosto de 2015, a través de la Ley 7.657 se creó el municipio de tercera categoría de Colonia Aborigen (Dellamea \& Cuadra, 2015) sobre parte del territorio de los departamentos Quitilipi y 25 de Mayo.

La Villa Rural El Palmar se ubica a 50 kilómetros al norte de la ciudad de Quitilipi; fue creada como una colonia rural en 1940, con la llegada de colonos inmigrantes y criollos, quienes se unieron a grupos aborígenes ya presentes en la zona. En 1951 se creó la Escuela № 435, alrededor de la cual se fue formando un pequeño núcleo urbano, que fue reconocido el 22 de mayo de 1966, cuando se produjo el acto fundacional, participando en el mismo el gobernador Deolindo Felipe Bittel; la comunidad local ha presentado en tres oportunidades proyectos para adquirir el estatus de municipio de tercera categoría. 


\subsection{Características físicas y climáticas}

El departamento Quitilipi integra, como toda la provincia del Chaco, la unidad fisiográfica denominada Región Chaqueña que abarca parte de los territorios de Argentina, Paraguay, Bolivia y Brasil. De las once subregiones ecológicas definidas para el Chaco (Morello \& Adamoli, 1970), Quitilipi se encuentra dentro de la subregión de Esteros, Cañadas y Selvas de Ribera, que corresponde a un relieve fluvial donde el modelo de vegetación adquiere un carácter anárquico; los bosques y pastizales aparecen pulverizados con catenas y gradientes angostos y límites netos entre tipos de vegetación. Es la región ecológica de mayor diversidad fisonómica de todo el Chaco, observándose la presencia de varios tipos de bosques y de pastizales; los lugares más altos fueron ocupados por la actividad agrícola. Una pequeña porción de superficie, ubicada al sureste del departamento, se ubica dentro de la región Deprimida.

La ciudad de Quitilipi, ubicada a los 2652'14" de latitud sur y 6012'54” de longitud oeste, se encuentra a 84 metros sobre el nivel del mar; el departamento es atravesado por la isoterma de $21^{\circ} \mathrm{C}$ y su régimen pluviométrico ronda los $1.060 \mathrm{~mm}$ anuales, con una máxima de $1.933 \mathrm{~mm}$ (1965/66) y una mínima de 608 mm (2008/09) (Administración Provincial del Agua - Dirección de Estudios Básicos, 2010).

Figura 2. Precipitaciones por año hidrológico. Periodo 1954/2010.

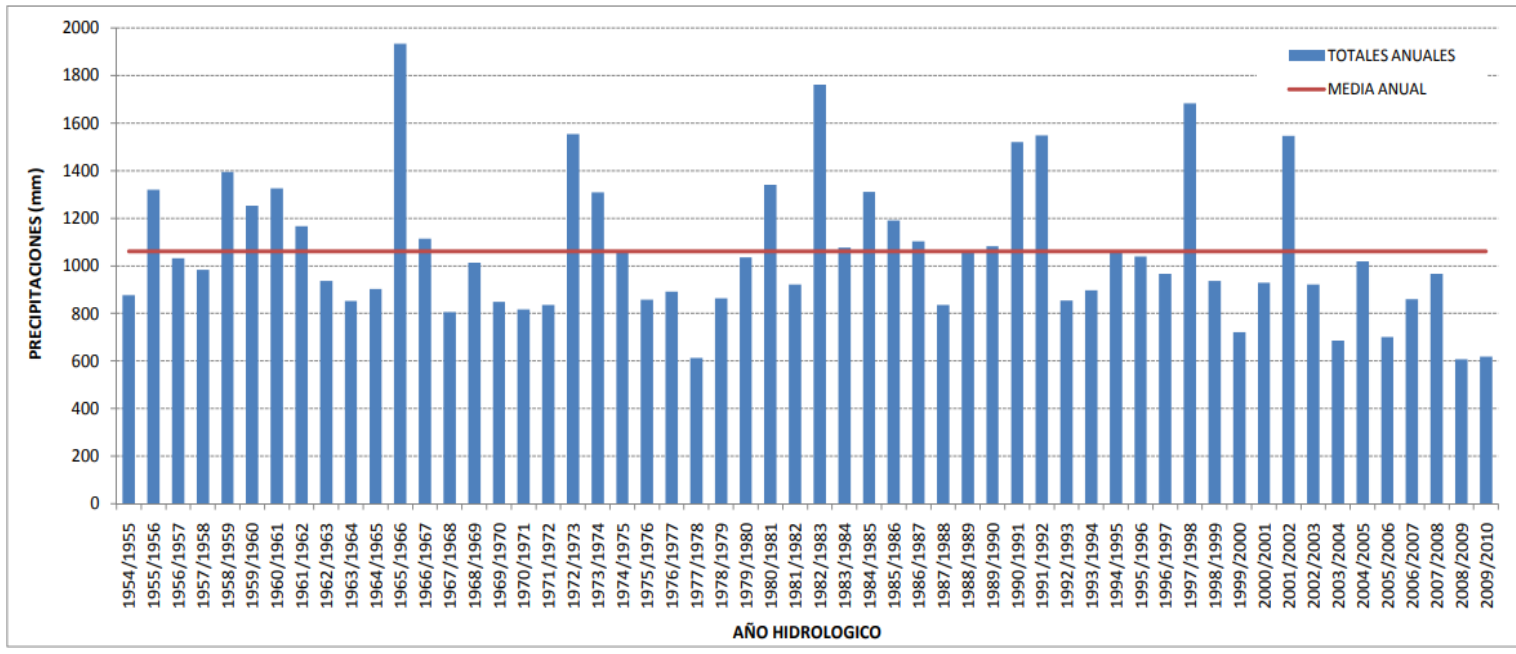

Fuente: Administración Provincial del Agua - Dirección de Estudios Básicos (2010).

\subsection{Dinámica demográfica}

El espacio en análisis era parte del territorio que ocupaban los abipones y, a partir de su expulsión en el siglo XVII, fue poblada por comunidades qom, mayormente, y moqoit, en menor medida; estas comunidades realizaban sus movimientos por la región siguiendo el ritmo de la naturaleza que los proveía de alimento, agua y abrigo. En la actualidad existe población qom en las colonias El Tacuruzal, La Matanza y Aborigen Chaco, amén de la propia ciudad de Quitilipi; en la Colonia Aborigen Chaco viven también familias de la etnia moqoit.

El territorio hoy ocupado por el departamento Quitilipi inició su poblamiento no originario en la primera década del siglo XX, recibiendo inmigración externa e interna para garantizar su ocupación, en gran medida auspiciado por el Estado nacional, que desde 1870 se encontraba en guerra con los pueblos originarios. En una primera etapa llegaron atraídos por la explotación forestal y posteriormente, a partir de la década de 1920, lo fue la producción algodonera; se reconoce como fecha de fundación de la ciudad el 30 de noviembre de 1912, fecha probable del arribo a ese lugar de las vías del Ferrocarril Central Norte Argentino. Este pueblo, juntamente con Presidencia Roque Sáenz Peña, se encontraba oficialmente fundado y, por lo tanto, tenía mensurada su planta urbana y sus habitantes podían acceder a la propiedad del predio que ocupaban, a diferencia de los pueblos establecidos en tierras fiscales y colonias nacionales que no lo estaban (Schaller, 1986).

Correntinos y paraguayos pasaron a constituir desde un primer momento una parte importante del componente social del territorio; en la segunda corriente inmigratoria, iniciada al promediar la segunda década del siglo XX, los españoles e italianos continuaron siendo las colectividades predominantes, de la misma manera que lo fueron también a nivel nacional. En la zona de Quitilipi los yugoslavos ${ }^{2}$-procedentes de la región de Montenegro-, tuvieron un peso importante en el componente inmigratorio de esta etapa, 2 Del serbocroata Jug: sur y Slavija: eslavo: eslavos del sur. 
ya que estos se radicaron en la zona central del Chaco (Mari, 2016).

Desde los comienzos de la colonización hasta la década de 1960, el algodón fue casi el único cultivo con cuya producción se avanzó en la ocupación de cerca de todo el territorio del Chaco, formándose así las colonias que rodearon a Quitilipi, pudiéndose afirmar que la población se agrupó prioritariamente en las áreas correspondiente a la capital provincial y en los centros algodoneros con mayor división de la tierra, entre los cuales se encontraba Quitilipi (OEA, 1977).

Este departamento muestra una variación poblacional positiva, influenciada por el aumento registrado en la ciudad cabecera, principal centro urbano de esta unidad territorial y cuya población (24.517 habitantes) representa el 72\% del total departamental.

En la Tabla 1 puede observarse la dinámica demográfica del departamento Quitilipi en el periodo 1947/2010; con altibajos, este departamento fue incrementado su población a lo largo del tiempo, con excepción de la década de 1960, momento en que se produce la primera gran crisis algodonera y el departamento pierde el $2 \%$ de su población, traccionado fuertemente por la pérdida de población rural, que fue del 15\%, a lo que se suma el registro pluviómetro record de la campaña 1965/66 (Figura 2). Con excepción de los periodos intercensales 1947/1960 y 1980/1991 -momento en que se produce la provincialización del Chaco y la creación del departamento en el primer periodo-, donde se registran aumentos de población rural, esta fue disminuyendo a lo largo del tiempo, habiéndose registrado una pérdida total en el ámbito rural de 5.547 personas (-58\%), en tanto que la población urbana se incrementó en 21.219 personas (+87\%) entre 1960 y 2010. Este fenómeno se encuentra asociado al aumento de población de los grandes centros urbanos y de las cabeceras departamentales que actúan como polo de atracción de una parte importante de la población proveniente del área rural y que se observa en toda la provincia del Chaco.

Tabla 1. Población urbana, rural y total del departamento Quitilipi. Total general y variación. Periodo 1947/2010.

\begin{tabular}{|c|c|c|c|c|c|c|c|}
\hline \multirow{2}{*}{ Año } & & \multicolumn{3}{|c|}{ Población } & \multicolumn{3}{|c|}{ Variación } \\
\cline { 3 - 8 } & & Urbana & Rural & Total & Urbana & Rural & Total \\
\hline \multirow{2}{*}{1947} & Total & 3.298 & 15.147 & 18.445 & & & \\
\cline { 2 - 8 } & $\%$ & $18 \%$ & $82 \%$ & $100 \%$ & & & \\
\hline \multirow{2}{*}{1960} & Total & 5.217 & 18.352 & 23.569 & 1.919 & 3.205 & 5.124 \\
\cline { 2 - 8 } & $\%$ & $22 \%$ & $78 \%$ & $100 \%$ & $37 \%$ & $17 \%$ & $22 \%$ \\
\hline \multirow{2}{*}{1970} & Total & 7.232 & 15.964 & 23.196 & 2.015 & -2.388 & -373 \\
\cline { 2 - 8 } & $\%$ & $31 \%$ & $69 \%$ & $100 \%$ & $28 \%$ & $-15 \%$ & $-2 \%$ \\
\hline \multirow{2}{*}{1980} & Total & 9.937 & 15.686 & 25.623 & 2.705 & -278 & 2.427 \\
\cline { 2 - 8 } & $\%$ & $39 \%$ & $61 \%$ & $100 \%$ & $27 \%$ & $-2 \%$ & $9 \%$ \\
\hline \multirow{2}{*}{1991} & Total & 14.055 & 15.840 & 29.895 & 4.118 & 154 & 4.272 \\
\cline { 2 - 8 } & $\%$ & $47 \%$ & $53 \%$ & $100 \%$ & $29 \%$ & $1 \%$ & $14 \%$ \\
\hline \multirow{2}{*}{2001} & Total & 21.540 & 10.543 & 32.083 & 7.485 & -5.297 & 2.188 \\
\cline { 2 - 8 } & $\%$ & $67 \%$ & $33 \%$ & $100 \%$ & $35 \%$ & $-50 \%$ & $7 \%$ \\
\hline \multirow{2}{*}{2010} & Total & 24.517 & 9.600 & 34.117 & 2.977 & -943 & 2.034 \\
\cline { 2 - 8 } & $\%$ & $72 \%$ & $28 \%$ & $100 \%$ & $12 \%$ & $-10 \%$ & $6 \%$ \\
\hline
\end{tabular}

Fuente: elaboración propia sobre la base de censos nacionales de población.

En 1991 la población rural todavía superaba a la población urbana, esta situación se revierte en el periodo intercensal 1991/2001, cuando se registró un aumento en el total de la población de 2.188 personas (7\%), pero mientras que el aumento en el área urbana fue de 7.485 personas (35\%), en el área rural se produjo una disminución de 5.297 personas (-50\%), lo que refleja el despoblamiento que sufrieron las áreas rurales del departamento, ocasionando que la participación de la población rural se redujese al 33\%, siendo superada por la población urbana. La pérdida de población rural en este periodo es coincidente con el inicio del proceso masivo de tecnologización que se dio en el cultivo algodonero, signado por la mecanización de la cosecha y el control químico de malezas e insectos, a lo que se sumaron dos campañas con lluvias superiores a las normales (1990/91 y 1991/92), seguidas de dos campañas secas (1992/93 y 1993/94) (Figura 2).

La población rural en el departamento Quitilipi hasta el 2001 representaba el 33\% de la población total, proporción que se situaba por encima de la Región Centro-Este (22\%), del promedio provincial (21\%), del promedio regional (24\%) y por encima del promedio del país en su conjunto (11\%) (CEPRODER, 2006). Esta situación continuaba hacia 2010, si bien estos guarismos se iban acercando, siendo de $28 \%$ en Quitilipi y $15 \%$ a nivel nacional.

El porcentaje de la población que vive en zonas consideradas rurales es un aspecto de importancia 
en la planificación de los servicios sociales, debido a que la dispersión de población en este ámbito incide negativamente en los costos y dificulta el acceso; si la ruralidad no constituye un déficit en sí misma, puede ser causa de situaciones deficitarias o dificultar su superación, aspecto estrechamente asociado con las situaciones de pobreza que caracterizan a las áreas rurales (Codutti, 2003).

\subsection{Estructura parcelaria}

Con la expansión de las actividades económicas, fundamentalmente forestal y algodonera, se inició el proceso de apropiación de la tierra pública, cuya estructura parcelaria refleja la evolución histórica que se ha manifestado. En Quitilipi existen 976 explotaciones agropecuarias (EAP) con límites definidos y reúnen una superficie de 131.046 hectáreas (República Argentina - INDEC, 2008); en relación al censo efectuado en 2002, surge una diferencia de -7.906 hectáreas, pero el mismo censo informa que las dos EAP ubicadas en el estrato de 2.500 a 5.000 hectáreas no cuentan con datos de superficie, por lo que es dable inferir que esa diferencia faltante podría encontrarse en estos dos establecimientos.

El 8 de junio de 1983 se sancionó la Ley $\mathrm{N}^{\circ} 2.822$ que refiere a la adjudicación de predios por parte del Instituto de Colonización y el 10 de enero de 1984 fue sancionada la Ley $\mathrm{N}^{\circ} 2.913$ que actualmente administra el régimen de tierras fiscales en la provincia; estas leyes dejaban de lado los concepto de “intrusos", establecido por el Decreto Ley $\mathrm{N}^{\circ} 2.040 / 1977$ y el de "unidad económica" al que refería el Decreto Ley $\mathrm{N}^{\circ} 1.094 / 1972$, exigiéndose para titularizar el predio la ocupación del mismo, independientemente de la superficie del mismo. En esta legislación podría encontrarse la explicación al aumento observado en las EAP de menos de 25 hectáreas en el periodo intercensal 1988/2001; la crisis de la agricultura que comienza a verificarse con el inicio del siglo XXI y la reconversión de productores agrícolas en ganaderos, o el abandono de la actividad, permitirían explicar la disminución ocurrida en el periodo 2001/2008.

Tabla 2. Establecimientos agropecuarios por estrato de superficie. Periodo 1960/2008.

\begin{tabular}{|c|c|c|c|c|c|c|c|c|c|c|}
\hline \multirow{2}{*}{ Estrato } & \multicolumn{2}{|c|}{1960} & \multicolumn{2}{|c|}{1969} & \multicolumn{2}{|c|}{1988} & \multicolumn{2}{c|}{2001} & \multicolumn{2}{c|}{2008} \\
\cline { 2 - 11 } & EAP & Ha & EAP & Ha & EAP & Ha & EAP & Ha & EAP & Ha \\
\hline $0,1-5$ & 48 & 184,00 & 107 & 352,90 & 22 & 89,00 & 54 & 217,00 & 42 & 169,50 \\
\hline $5,1-25$ & 396 & $7.111,00$ & 376 & $6.346,50$ & 127 & 2254,60 & 245 & $4.010,60$ & 199 & $3.563,00$ \\
\hline $\begin{array}{c}25,1- \\
100\end{array}$ & 902 & $57.848,00$ & 841 & $55.106,20$ & 484 & 31529,30 & 450 & $28.460,60$ & 428 & $27.862,80$ \\
\hline $\begin{array}{c}100,1- \\
200\end{array}$ & 131 & $20.574,00$ & 189 & $28.783,00$ & 176 & 26863,80 & 170 & $25.609,40$ & 160 & $24.485,00$ \\
\hline $\begin{array}{c}200,1- \\
500\end{array}$ & 19 & $5.770,00$ & 51 & $15.550,00$ & 120 & 37217,40 & 117 & $36.724,50$ & 98 & $32.377,80$ \\
\hline $\begin{array}{c}500,1- \\
1.000\end{array}$ & 6 & $3.329,00$ & 19 & $10.593,00$ & 33 & 23213,70 & 38 & $26.004,50$ & 35 & $23.606,00$ \\
\hline $\begin{array}{c}1.000,1- \\
2.500\end{array}$ & 2 & $2.350,00$ & 5 & $7.873,00$ & 8 & 11053,70 & 11 & $17.925,70$ & 12 & $18.982,00$ \\
\hline $\begin{array}{c}2.500,1 \\
-5,000\end{array}$ & 1 & $5.000,00$ & 0 & 0,00 & 0 & 0,00 & 0 & 0,00 & 2 & s/d \\
\hline Total: & 1.505 & $102.166,00$ & 1.588 & $124.604,60$ & 970 & $132.221,50$ & 1.085 & $138.952,30$ & 976 & $131.046,10$ \\
\hline
\end{tabular}

Fuente: elaboración propia en base a censos nacionales agropecuarios.

El proceso de apropiación de la tierra pública que acompañó la ocupación territorial fue enmarcada legalmente durante la primera mitad del siglo XX por las leyes 4.167 y 5.559. La primera de éstas, sancionada en 1903, tuvo el objetivo de corregir el manejo administrativo de la tierra fiscal, producto de esto se estableció la exploración y la mensura de todo terreno fiscal antes de su adjudicación, determinando que las tierras podían ser destinadas a la explotación agrícola o ganadera; en el primer caso, los terrenos eran fraccionados en lotes de 100 hectáreas, mientras que las áreas pastoriles se dividían en lotes de 625 o 2.500 ha (República Argentina - Congreso Nacional, 1876). Esto impedía a los pequeños productores el acceso a la propiedad de la tierra.

Los descendientes de inmigrantes, cargados de una lógica productiva de maximización de ganancias, tomaron la mayor cantidad de tierras que les estaba permitido tomar, en tanto que los correntinos y paraguayos, con una lógica asociada al buen vivir, solo tomaron aquello que iban a trabajar y que les permitía reproducirse, sin ánimo de acumular, siguiendo lo expresado por Chayanov, respecto que el campesino trabaja hasta satisfacer sus necesidades y, luego, deja de trabajar (Chayanov, (1925) 1985; Martínez, 2018).

La cantidad de EAP a lo largo del tiempo es errático según cada estrato; en el agrupamiento de menos 
de 25 hectáreas, se observan aumentos y disminuciones en la cantidad de establecimientos. Con excepción del periodo intercensal 1960/69, donde el estrato de menos de 5 hectáreas aumentó considerablemente y el comprendido entre 5,1 y 25 hectáreas sufrió una disminución en la cantidad de EAP, los periodos siguientes se correlacionan positivamente, aumentando y disminuyendo en las mismas etapas.

El estrato de 25,1 a 100 hectáreas, el más importante en cantidad de EAP, fue disminuyendo en forma permanente y el de 100,1 a 200 hectáreas tuvo un incremente en el periodo 1960/69 para luego acompañar la caída del estrato anterior. Los agrupamientos 200,1-500 y 500,1-1.000 hectáreas fueron aumentando en cantidad de establecimientos hasta el censo 2001, disminuyendo en el 2008; una explicación a esta disminución puede encontrarse en que este sector, de agricultores mecanizados, durante la década de 1990 se endeudó con créditos hipotecarios en las entidades bancarias, debiendo vender parte o la totalidad del campo para poder pagar esas deudas (Martínez, 2018).

El estrato de 1.000,1-2.500 hectáreas mantuvo un crecimiento sostenido a lo largo del tiempo, en tanto que el de más de 2.500,1 hectáreas tuvo un EAP en 1960, desapareciendo luego para reaparecer con dos establecimientos en 2008. Estos EAP, dedicados casi exclusivamente a la actividad ganadera extensiva, requieren de mayor superficie para dedicarse a la misma, lo que se constituye en una atracción para la concentración de la tierra.

Figura 3. Evolución en la cantidad de EAP por estrato. Periodo 1960/2008.

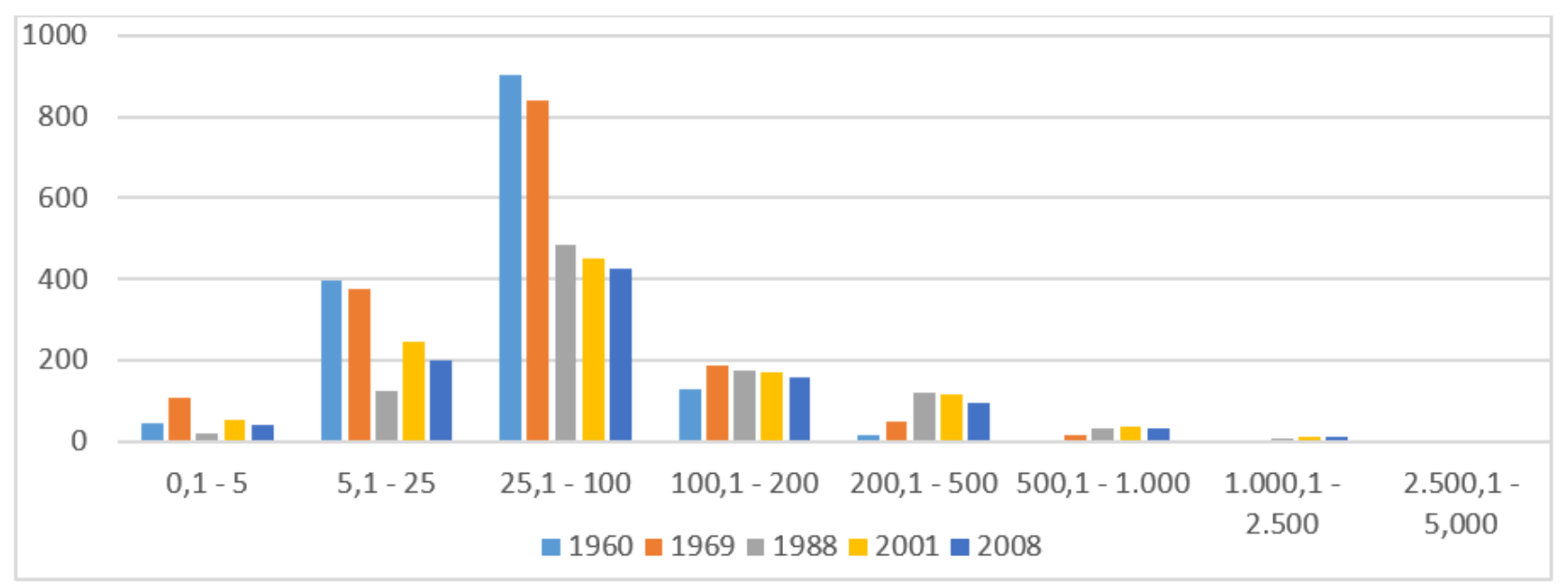

Fuente: elaboración propia en base a censos nacionales.

Tabla 3. Cantidad de EAP y superficie en valores absolutos y relativos, por estrato. Año 2008.

\begin{tabular}{|c|c|c|c|c|c|c|}
\hline Estrato (Ha) & $\begin{array}{c}\text { Cantidad } \\
\text { EAP }\end{array}$ & $\%$ & $\%$ acumulado & $\begin{array}{c}\text { Superficie } \\
\text { (Ha) }\end{array}$ & $\%$ & $\begin{array}{c}\% \\
\text { acumulado }\end{array}$ \\
\hline Menos de 5 & 42 & $4,30 \%$ & $4,30 \%$ & 169,50 & $0,13 \%$ & $0,13 \%$ \\
\hline $5,1-10$ & 44 & $4,51 \%$ & $8,81 \%$ & 360,00 & $0,27 \%$ & $0,40 \%$ \\
\hline $10,1-25$ & 155 & $15,88 \%$ & $24,69 \%$ & 3203,00 & $2,44 \%$ & $2,85 \%$ \\
\hline $25,1-50$ & 178 & $18,24 \%$ & $42,93 \%$ & 7438,80 & $5,68 \%$ & $8,52 \%$ \\
\hline $50,1-100$ & 250 & $25,61 \%$ & $68,55 \%$ & 20424,00 & $15,59 \%$ & $24,11 \%$ \\
\hline $100,1-200$ & 160 & $16,39 \%$ & $84,94 \%$ & 24485,00 & $18,68 \%$ & $42,79 \%$ \\
\hline $200,1-500$ & 98 & $10,04 \%$ & $94,98 \%$ & 32377,80 & $24,71 \%$ & $67,50 \%$ \\
\hline $500,1-1.000$ & 35 & $3,59 \%$ & $98,57 \%$ & 23606,00 & $18,01 \%$ & $85,52 \%$ \\
\hline $1.000,1-$ & 12 & $1,23 \%$ & $99,80 \%$ & 18982,00 & $14,48 \%$ & $100,00 \%$ \\
\hline 2.500 & 2 & $0,20 \%$ & $100,00 \%$ & $s / d$ & $s / d$ & s/d \\
\hline $\begin{array}{c}\text { Más de } \\
2.500,1\end{array}$ & 976 & $100,00 \%$ & & $131.046,10$ & $100,00 \%$ & \\
\hline Total: & & & & & \\
\hline
\end{tabular}

Fuente: Elaboración propia en base a (República Argentina - INDEC, 2008).

Durante la presidencia de Onganía se sancionó la Ley Raggio3 (en realidad decreto-ley) en 1967, la que terminó con los arrendatarios estables (Barrado, 2006), impulsando un proceso a nivel nacional de concentración de la tierra al cual no escapó la provincia del Chaco. Esto ocasionó que en Quitilipi el 69\% de las EAP (669 establecimientos), que tienen menos de 100 hectáreas, solamente administren el 24\% de $\overline{3}$ Ministro de Agricultura durante el gobierno del presidente de facto Juan Carlos Onganía. 
la tierra, mientras que, en el extremo opuesto, el 33\% de la tierra se encuentra en poder del 5\% de las EAP (49 establecimientos). De verificarse que las dos EAP de más de 2.500 hectáreas poseen aproximadamente 7.900 hectáreas de tierra en total, esto representaría, por sí solo, el 6\% de la superficie ocupada.

El censo nacional agropecuario realizado en 2018 no estratifica las EAP por superficie, solamente permite conocer la cantidad de establecimientos por departamento y provincia. En el Chaco, entre 2002 y 2018 se perdió un 31\% de EAP (Martínez \& Cuadra, 2021) ${ }^{4}$; en el departamento Quitilipi, la pérdida de establecimientos agropecuarios en ese mismo periodo fue del 54\%. La variación en el periodo analizado puede observarse en la Tabla 4, donde puede verse que en el último periodo intercensal se perdieron 481 EAP, lo que representa un $49 \%$ menos respecto del inicio del periodo.

Tabla 4. Variación en la cantidad de EAP en valores absolutos y relativos.

\begin{tabular}{|c|c|c|c|c|c|c|}
\hline \multirow{2}{*}{ Año } & \multirow{2}{*}{ EAP } & \multicolumn{2}{|c|}{ Variación } & \multirow{2}{*}{$\begin{array}{c}\text { Superficie } \\
\text { (ha) }\end{array}$} & & \multicolumn{2}{c|}{ Variación } \\
& & Absoluta & Relativa & Absoluta & Relativa \\
\hline 1960 & 1.510 & & & $102.166,0$ & & \\
\hline 1969 & 1.588 & 78 & $5 \%$ & $124.604,6$ & $22.438,6$ & $22 \%$ \\
\hline 1988 & 970 & -618 & $-39 \%$ & $132.221,5$ & $7.616,9$ & $6 \%$ \\
\hline 2001 & 1.085 & 115 & $12 \%$ & $138.952,3$ & $6.730,8$ & $5 \%$ \\
\hline 2008 & 976 & -109 & $-10 \%$ & $131.046,1$ & $-7.906,2$ & $-6 \%$ \\
\hline 2018 & 495 & -481 & $-49 \%$ & $97.034,7$ & $-34.011,4$ & $-26 \%$ \\
\hline
\end{tabular}

Fuente: elaboración propia en base a censos agropecuarios.

La disminución observada en el último periodo puede deberse a dos razones. En cuanto a la primera conjetura, consultas realizadas a encuestadores indican varias dificultades operativas que debieron enfrentar en la realización de las actividades censales en 2018: falta de entrenamiento previo en el uso de las tablets para levantar los datos; cuestionario muy extenso que hacía que el productor perdiera la paciencia y respondiera negando actividades; respuestas minimizadas y evasivas por parte de los encuestados, atribuibles al temor o presunción de represalias impositivas si declaraban los datos reales de su explotación. Respecto a la segunda conjetura, en las últimas décadas en el centro este de la provincia del Chaco, muchas de las pequeñas explotaciones dedicadas a la agricultura fueron fagocitadas por unidades más grandes, para anexarlas a la actividad pecuaria y, en consecuencia, se fue produciendo una sustitución de usos del suelo y, en otros casos, directamente esas tierras quedaron fuera de producción (Martínez \& Cuadra, 2021).

La distribución de los productores en el territorio obedece al perfil productivo de cada colonia, así la mayor presencia de estos se encuentra vinculada a las colonias donde mayor era la actividad agrícola, destacándose también en estas la mayor presencia de productores de escasa superficie, asociada a que estos eran mano de obra temporaria para tareas de carpida y cosecha en establecimientos de mayor escala.

Tabla 5. Distribución de productores por colonia. Año 2020.

\begin{tabular}{|c|c|c|c|}
\hline \multirow{2}{*}{ Colonia } & \multicolumn{3}{|c|}{$\begin{array}{c}\text { Cantidad de productores por } \\
\text { estrato de superficie ocupada }\end{array}$} \\
\cline { 2 - 4 } & $\begin{array}{c}\text { Menos } \\
10 \text { ha }\end{array}$ & $\begin{array}{c}\text { Entre 10,1 y } \\
50 \text { ha }\end{array}$ & $\begin{array}{c}\text { Más de } \\
50,1 \text { ha }\end{array}$ \\
\hline El Tacuruzal & 247 & 58 & 62 \\
\hline General Paz & 166 & 36 & 12 \\
\hline La Matanza & 125 & 31 & 19 \\
\hline La Tambora & 78 & 36 & 10 \\
\hline $\begin{array}{c}\text { Aborigen La } \\
\text { Matanza }\end{array}$ & 66 & 0 & 0 \\
\hline Aborigen Chaco & 40 & 0 & 0 \\
\hline Uriburu & 17 & 31 & 37 \\
\hline Bajo Hondo & 15 & 7 & 7 \\
\hline
\end{tabular}

$4 \quad$ A pesar de las objeciones que se han hecho a la información arrojada por este censo, donde Chaco fue una de las pocas provincias que lo finalizó, se toman los datos de establecimientos agropecuarios por ser esta una información en la que se coincide que hay un alto grado de certeza. El artículo de referencia corresponde a una investigación realizada en todas las provincias desde la Cátedra Libre de Estudios Agrarios “Ingeniero Horacio Giberti” (UBA), donde por las objeciones realizadas se tomó el periodo 20022018. 


\begin{tabular}{|c|c|c|c|}
\hline Blas Parera & 11 & 4 & 5 \\
\hline Campo Feldman & 0 & 1 & 11 \\
\hline $\begin{array}{c}\text { Remedios Escalada } \\
\text { de San Martín }\end{array}$ & 4 & 1 & 2 \\
\hline TOTAL: & 769 & 205 & 165 \\
\hline
\end{tabular}

Fuente: elaboración propia en base a (Limito, 2020).

El mayor número de productores en relación a las EAP, obedece al concepto de núcleos de agricultores familiares que es tomado por el Registro Nacional de Agricultura Familiar, que considera a la familia que trabaja como un núcleo familiar, independientemente del tipo de tenencia de la tierra; así en un mismo EAP pueden trabajar varias familias.

\subsection{Dinámica productiva}

\subsubsection{Agricultura}

El departamento Quitilipi reúne 80.500 hectáreas (52\%) de suelos con aptitud agrícola, los que ofrecen limitaciones ligeras a moderadas para el desarrollo de esta actividad; la superficie de uso ganadero forestal alcanza las 74.000 hectáreas (48\%), aspecto que se encuentra asociado con la superficie de esta jurisdicción incluida en la subregión ecológica Dorsal Agrícola Subhúmeda (Codutti, 2003).

Guido Miranda (1955) expresa que el Territorio Nacional del Chaco fue una frontera agraria impulsada por el cultivo algodonero y la producción industrial de la caña de azúcar y taninera; los cultivos agrícolas junto con el trazado del ferrocarril, las colonias y la mensura de la tierra, convirtieron al Chaco en una región económica marginal nordestina. El algodón, cuyo cultivo se inició en la década de 1920, contribuyó con la formación de pueblos y colonias agrícolas, como ya se señalara, contribuyendo al poblamiento departamental; la importancia de este cultivo llevo a que cada pueblo fuera teniendo por lo menos una cooperativa de comercialización, que era al mismo tiempo de consumo, vendiendo a sus socios mercaderías a mejores precios. En 1925 surgió la Cooperativa Agropecuaria Unión y Trabajo Ltda. (OEA, 1977), la que aún brinda servicio de desmote de algodón a productores de Quitilipi y otras zonas.

Luego de la primera gran crisis algodonera iniciada a finales de la década de 1950, se pasó de cultivar 31.055 hectáreas en la campaña 1959/60 a 11.500 hectáreas diez años más tarde, teniendo importantes incrementos el sorgo (10.000 hectáreas), el girasol (6.500 hectáreas) y el trigo (aparece en las estadísticas con 5.500 hectáreas), dando inicio en el departamento al proceso de "pampeanización" que ocurriera en la llanura chaqueña (Cuadra, Bonfanti, Andrada, Golemba, \& Vera, 2015).

Pese a lo anterior, hasta finales de la década de 1960 el algodón continuó siendo el principal cultivo departamental, aunque con una fuerte presencia sembrada de sorgo; es a partir de la campaña agrícola 1970/71 cuando se impone el girasol como principal cultivo, situación que se mantiene por seis campañas. A partir de 1976/77 el algodón recupera su primacía, la que mantiene hasta la campaña 1998/99, alcanzando un record del 84\% de la superficie cultivada total en el departamento en la campaña 1990/91, con 27.000 hectáreas, aunque fue en la campaña 1978/79 en que el textil alcanzó el record absoluto en superficie, con 35.000 hectáreas, representando el 75\% de la superficie sembrada.

Entre las campañas 1999/2000 y 2004/05, la soja alcanza el primer lugar de siembra, con la salvedad que en la campaña 2003/04 igualó la superficie sembrada con el girasol (15.000 ha cada uno); el algodón vuelve al primer lugar en la campaña 2005/06 y siguiente, volviendo a ser desplazado por la soja en 2007/08 y recuperando primacía en 2008/09 hasta la campaña 2013/14, siendo superado por la soja en las campañas 2011/2012 y 2014/15. A partir de 2015/16 el girasol pasó a ser el cultivo principal en Quitilipi hasta la campaña agrícola 2019/20, en que el algodón recuperó el liderazgo.

Tabla 6. Superficie sembrada en el departamento Quitilipi. Periodo 1969/2019.

\begin{tabular}{|c|c|c|c|c|c|c|c|c|c|}
\hline Campaña & Algodón & Girasol & Soja & $\begin{array}{c}\text { Otros } \\
\text { cultivos } \\
\text { industriales }\end{array}$ & Maíz & Sorgo & Trigo & $\begin{array}{c}\text { Otros } \\
\text { cereales }\end{array}$ & Hortalizas \\
\hline $1959 / 60$ & 31.055 & 354 & s/d & 84 & 3.536 & 109 & s/d & 5 & 674 \\
\hline $1969 / 70$ & 11.500 & 6.500 & 10 & s/d & 2.000 & 10.000 & 5.500 & 200 & 435 \\
\hline $1970 / 71$ & 8.500 & 16.500 & 10 & s/d & 2.200 & 8.500 & 4.800 & 150 & 240 \\
\hline
\end{tabular}




\begin{tabular}{|c|c|c|c|c|c|c|c|c|c|}
\hline $1971 / 72$ & 11.000 & 17.000 & 30 & $\mathrm{~s} / \mathrm{d}$ & 1.500 & 6.500 & 5.000 & 200 & 145 \\
\hline $1972 / 73$ & 12.000 & 21.000 & 100 & 250 & 1.000 & 4.000 & 5.500 & 250 & 167 \\
\hline $1973 / 74$ & 16.000 & 17.000 & 100 & 300 & 900 & 5.000 & 3.500 & 450 & 150 \\
\hline $1974 / 75$ & 14.000 & 18.000 & 80 & 200 & 800 & 4.500 & 3.000 & 400 & 165 \\
\hline $1975 / 76$ & 12.000 & 23.000 & 130 & 50 & 350 & 7.000 & 3.500 & 300 & 62 \\
\hline 1976/77 & 16.000 & 12.000 & 110 & $\mathrm{~s} / \mathrm{d}$ & 350 & 8.500 & 350 & 30 & 96 \\
\hline $1977 / 78$ & 20.000 & 10.000 & 60 & 75 & 1.900 & 2.500 & 1.525 & 170 & 810 \\
\hline $1978 / 79$ & 35.000 & 6.700 & 30 & 90 & 1.700 & 2.200 & 150 & 170 & 488 \\
\hline $1979 / 80$ & 27.000 & 9.400 & 40 & 70 & 1.900 & 2.000 & 200 & 100 & 480 \\
\hline $1980 / 81$ & 15.000 & 7.500 & $\mathrm{~s} / \mathrm{d}$ & 40 & 3.000 & 6.000 & 600 & 100 & 332 \\
\hline $1981 / 82$ & 23.000 & 6.000 & $\mathrm{~s} / \mathrm{d}$ & 17 & 3.000 & 10.000 & 400 & 100 & 281 \\
\hline $1982 / 83$ & 21.000 & 9.500 & 100 & $\mathrm{~s} / \mathrm{d}$ & 2.000 & 7.000 & 600 & 100 & 21 \\
\hline 1983/84 & 24.000 & 1.600 & 100 & $\mathrm{~s} / \mathrm{d}$ & 2.000 & 7.150 & $\mathrm{~s} / \mathrm{d}$ & $\mathrm{s} / \mathrm{d}$ & 3 \\
\hline $1984 / 85$ & 24.000 & 6.000 & $\mathrm{~s} / \mathrm{d}$ & $\mathrm{s} / \mathrm{d}$ & 1.750 & 7.000 & 200 & $\mathrm{~s} / \mathrm{d}$ & $\mathrm{s} / \mathrm{d}$ \\
\hline $1985 / 86$ & 12.000 & 9.000 & $\mathrm{~s} / \mathrm{d}$ & $\mathrm{s} / \mathrm{d}$ & 1.700 & 3.500 & 150 & $\mathrm{~s} / \mathrm{d}$ & $\mathrm{s} / \mathrm{d}$ \\
\hline $1986 / 87$ & 7.000 & 4.000 & $\mathrm{~s} / \mathrm{d}$ & $\mathrm{s} / \mathrm{d}$ & 1.700 & 1.500 & 200 & $\mathrm{~s} / \mathrm{d}$ & $\mathrm{s} / \mathrm{d}$ \\
\hline $1987 / 88$ & 24.000 & 7.000 & 250 & $\mathrm{~s} / \mathrm{d}$ & 1.800 & 1.700 & 150 & $\mathrm{~s} / \mathrm{d}$ & $\mathrm{s} / \mathrm{d}$ \\
\hline $1988 / 89$ & 24.000 & 1.200 & 2.500 & $\mathrm{~s} / \mathrm{d}$ & 1.800 & 6.500 & 30 & $s / d$ & 7 \\
\hline 1989/90 & 23.000 & 4.500 & 2.100 & $\mathrm{~s} / \mathrm{d}$ & 2.000 & 2.700 & 800 & $\mathrm{~s} / \mathrm{d}$ & 12 \\
\hline 1990/91 & 27.500 & 2.300 & 1.000 & $\mathrm{~s} / \mathrm{d}$ & $\mathrm{s} / \mathrm{d}$ & 2.000 & $\mathrm{~s} / \mathrm{d}$ & $\mathrm{s} / \mathrm{d}$ & 14 \\
\hline $1991 / 92$ & 25.000 & 1.500 & 1.400 & $\mathrm{~s} / \mathrm{d}$ & $\mathrm{s} / \mathrm{d}$ & 2.500 & 500 & $\mathrm{~s} / \mathrm{d}$ & 18 \\
\hline 1992/93 & 15.500 & 1.500 & 2.000 & $\mathrm{~s} / \mathrm{d}$ & $\mathrm{s} / \mathrm{d}$ & 2.200 & 500 & $\mathrm{~s} / \mathrm{d}$ & 18 \\
\hline $1993 / 94$ & 20.000 & 600 & 4.000 & $\mathrm{~s} / \mathrm{d}$ & 2.000 & 1.300 & 700 & $\mathrm{~s} / \mathrm{d}$ & 18 \\
\hline 1994/95 & 23.000 & 3.000 & 4.500 & $\mathrm{~s} / \mathrm{d}$ & 2.000 & 1.000 & 1.500 & $\mathrm{~s} / \mathrm{d}$ & 12 \\
\hline 1995/96 & 18.000 & 1.200 & 2.500 & $\mathrm{~s} / \mathrm{d}$ & 3.500 & 500 & 700 & $\mathrm{~s} / \mathrm{d}$ & 2 \\
\hline 1996/97 & 20.000 & 1.500 & 6.000 & $\mathrm{~s} / \mathrm{d}$ & 4.000 & 1.500 & 2.000 & $\mathrm{~s} / \mathrm{d}$ & 12 \\
\hline $1997 / 98$ & 23.000 & 2.000 & 6.000 & $\mathrm{~s} / \mathrm{d}$ & 2.500 & 1.000 & 1.350 & $\mathrm{~s} / \mathrm{d}$ & 12 \\
\hline $1998 / 99$ & 15.000 & 9.000 & 10.000 & $\mathrm{~s} / \mathrm{d}$ & 3.000 & 1.500 & 1.000 & $\mathrm{~s} / \mathrm{d}$ & $\mathrm{s} / \mathrm{d}$ \\
\hline 1999/00 & 6.750 & 6.400 & 15.000 & $\mathrm{~s} / \mathrm{d}$ & 4.000 & 1.000 & 1.000 & $\mathrm{~s} / \mathrm{d}$ & $\mathrm{s} / \mathrm{d}$ \\
\hline 2000/01 & 11.400 & 5.000 & 20.000 & 6 & 3.000 & 1.000 & 2.000 & $\mathrm{~s} / \mathrm{d}$ & 480 \\
\hline $2001 / 02$ & 4.200 & 7.000 & 25.000 & $\mathrm{~s} / \mathrm{d}$ & 3.500 & 1.000 & 5.000 & $\mathrm{~s} / \mathrm{d}$ & $\mathrm{s} / \mathrm{d}$ \\
\hline $2002 / 03$ & 2.200 & 12.000 & 31.000 & $\mathrm{~s} / \mathrm{d}$ & 4.000 & 2.000 & 7.000 & $\mathrm{~s} / \mathrm{d}$ & $\mathrm{s} / \mathrm{d}$ \\
\hline $2003 / 04$ & 4.300 & 15.000 & 15.000 & $\mathrm{~s} / \mathrm{d}$ & 4.000 & 2.000 & 7.000 & $\mathrm{~s} / \mathrm{d}$ & $\mathrm{s} / \mathrm{d}$ \\
\hline $2004 / 05$ & 7.230 & 7.000 & 27.266 & $\mathrm{~s} / \mathrm{d}$ & 3.000 & 3.500 & 100 & $\mathrm{~s} / \mathrm{d}$ & $\mathrm{s} / \mathrm{d}$ \\
\hline 2005/06 & 13.100 & 5.800 & 7.800 & $\mathrm{~s} / \mathrm{d}$ & 3.500 & 2.000 & 3.500 & $\mathrm{~s} / \mathrm{d}$ & $\mathrm{s} / \mathrm{d}$ \\
\hline 2006/07 & 20.300 & 5.670 & 7.500 & $\mathrm{~s} / \mathrm{d}$ & 5.000 & 2.500 & 6.000 & $\mathrm{~s} / \mathrm{d}$ & $\mathrm{s} / \mathrm{d}$ \\
\hline $2007 / 08$ & 4.840 & 3.500 & 9.000 & $\mathrm{~s} / \mathrm{d}$ & 4.000 & 4.000 & 200 & $\mathrm{~s} / \mathrm{d}$ & $\mathrm{s} / \mathrm{d}$ \\
\hline 2008/09 & 13.800 & 2.500 & 9.950 & $\mathrm{~s} / \mathrm{d}$ & 3.500 & 4.000 & $\mathrm{~s} / \mathrm{d}$ & $\mathrm{s} / \mathrm{d}$ & $\mathrm{s} / \mathrm{d}$ \\
\hline 2009/10 & 17.000 & 1.400 & 8.200 & $\mathrm{~s} / \mathrm{d}$ & 3.600 & 4.150 & $\mathrm{~s} / \mathrm{d}$ & $\mathrm{s} / \mathrm{d}$ & $\mathrm{s} / \mathrm{d}$ \\
\hline $2010 / 11$ & 15.500 & 4.000 & 6.300 & $\mathrm{~s} / \mathrm{d}$ & 2.300 & 2.300 & 2.600 & $\mathrm{~s} / \mathrm{d}$ & $\mathrm{s} / \mathrm{d}$ \\
\hline $2011 / 12$ & 3.700 & 7.000 & 9.000 & $\mathrm{~s} / \mathrm{d}$ & 2.500 & 2.300 & 1.800 & $\mathrm{~s} / \mathrm{d}$ & $\mathrm{s} / \mathrm{d}$ \\
\hline $2012 / 13$ & 12.000 & 2.000 & 4.350 & $\mathrm{~s} / \mathrm{d}$ & 2.650 & 4.000 & 800 & $\mathrm{~s} / \mathrm{d}$ & $\mathrm{s} / \mathrm{d}$ \\
\hline $2013 / 14$ & 14.000 & 1.600 & 4.500 & $\mathrm{~s} / \mathrm{d}$ & 2.500 & 4.000 & 200 & $\mathrm{~s} / \mathrm{d}$ & $\mathrm{s} / \mathrm{d}$ \\
\hline $2014 / 15$ & 6.000 & 3.500 & 6.585 & $\mathrm{~s} / \mathrm{d}$ & 1.250 & 1.530 & 1.500 & $\mathrm{~s} / \mathrm{d}$ & $\mathrm{s} / \mathrm{d}$ \\
\hline $2015 / 16$ & 3.500 & 5.450 & 4.500 & $\mathrm{~s} / \mathrm{d}$ & 2.770 & 500 & 1.380 & $\mathrm{~s} / \mathrm{d}$ & $\mathrm{s} / \mathrm{d}$ \\
\hline $2016 / 17$ & 3.520 & 8.000 & 4.327 & $\mathrm{~s} / \mathrm{d}$ & 400 & 185 & 1.000 & $\mathrm{~s} / \mathrm{d}$ & $\mathrm{s} / \mathrm{d}$ \\
\hline $2017 / 18$ & 1.280 & 8.189 & 1.070 & $\mathrm{~s} / \mathrm{d}$ & 1.590 & 1.110 & 1.000 & $\mathrm{~s} / \mathrm{d}$ & $\mathrm{s} / \mathrm{d}$ \\
\hline $2018 / 19$ & 2.763 & 5.605 & 4.570 & $\mathrm{~s} / \mathrm{d}$ & 1.830 & 676 & 750 & $\mathrm{~s} / \mathrm{d}$ & $\mathrm{s} / \mathrm{d}$ \\
\hline
\end{tabular}




\begin{tabular}{|l|l|l|l|l|l|l|l|l|l|}
\hline $2019 / 20$ & 4.000 & 3.500 & $\mathrm{~s} / \mathrm{d}$ & $\mathrm{s} / \mathrm{d}$ & 1.900 & 800 & 1.000 & $\mathrm{~s} / \mathrm{d}$ & $\mathrm{s} / \mathrm{d}$ \\
\hline
\end{tabular}

Fuente: elaboración propia en base a (República Argentina - Dirección Nacional de Estadística y Censos, 1964; República Argentina - MAGyP, 2020).

Luego de alcanzar un record histórico en superficie sembrada que se verificó en la campaña 2002/2003, coincidente con la salida de la convertibilidad ${ }^{5}$, donde la soja contribuyó con su propio record de 31.000 hectáreas, la superficie sembrada comenzó a decaer, siendo en la campaña 2019/2020 de solo 11.200 hectáreas, lo que representa el 31\% de la superficie cultivada en la campaña 1959/60 y el 19\% de la campaña histórica 2002/03.

Hasta inicios de la década de 1970, Quitilipi era la Capital del Algodón; la pérdida de importancia de este cultivo se verifica en el hecho que en la campaña 1985/86, eran catorce los departamentos de la provincia en los que el cultivo predominante era el algodón; en la campaña agrícola 2013/14, Quitilipi fue una de las cinco jurisdicciones que aún tenían al algodón como cultivo predominante, juntamente con Libertador General San Martín, Fray Justo Santa María de Oro, Mayor Luis Fontana y Presidencia de la Plaza (Cuadra, Bonfanti, Andrada, Golemba, \& Vera, 2015). Pese a que la base de producción agrícola sufriera modificaciones como consecuencia de la evolución de los precios relativos de los productos y el margen neto de las diferentes actividades, en el departamento Quitilipi el algodón continuaba resistiendo, aunque esa fue la última campaña donde mostró su preeminencia, iniciando un camino de declinación al que también contribuyera la aparición del picudo del algodonero. Una muestra de esta situación se encuentra en que de nueve desmotadoras que funcionaron en su momento, para el 2020 solamente funcionaron dos de ellas (Cooperativa Agropecuaria Unión y Trabajo Ltda. y Heller Norteña).

Los cultivos industriales fueron predominantes en el departamento, aportando el $78 \%$ de la superficie histórica sembrada; a ese porcentaje contribuyó el algodón con el 54\%, el girasol con el 26\% y la soja con el 20\%. En Quitilipi se sembraron otros cultivos industriales, pero su presencia no fue significativa, así en la campaña 1959/60 se sembraron 41 hectáreas de tártago, entre las campañas 1972/73 y 1975/76 se sembró cártamo con un promedio anual de 200 hectáreas y entre las campañas 1977/78 y 1981/82 se implantó tabaco rubio, promediando 54 hectáreas; en la campaña 2000/01 se registraron 6 hectáreas sembradas de este último cultivo.

El aporte de los cereales representó el 22\% de la superficie, donde el sorgo aportó el 46\%, el maíz el $30 \%$, el trigo lo hizo con el $23 \%$ y otros cereales sumaron el restante $1 \%$; entre estos se menciona avena, cebada y centeno, con 128, 65 y 82 hectáreas promedio respectivamente, todo ellos con destino forrajero.

Si bien la participación del área hortícola pareciera ser insignificante, vale remarcar que esta no es totalmente relevada en las estadísticas, permaneciendo invisibilizada por ser producción que se destina, preferentemente, al autoconsumo familiar y a la comercialización, preponderantemente en el mercado local, por lo que tiene una destacada importancia desde el punto de vista social y económico para la pequeña agricultura familiar, mereciendo recalcar que desde principios de este siglo funciona una feria franca en la ciudad de Quitilipi donde los productores comercializan su producción directamente al consumidor.

\subsubsection{Ganadería}

La declinación de la actividad agrícola llevó a los productores a iniciar un camino de reconversión; una de las actividades a la que se volcaron fue la ganadería, rubro que ya se desarrollaba en la zona de la mano de la gran propiedad, dedicada exclusivamente a esta actividad, hasta aquella articulada con la agricultura en los sistemas asociados a la mediana y pequeña producción familiar (Codutti, 2003).

$\overline{5} \quad$ Ley implantada en el año 1991, que ataba el tipo de cambio del peso argentino al dólar estadounidense en una paridad de uno a uno; fue derogada en enero de 2002. 
Figura 4. Evolución del rodeo bovino. Periodo 1960/2020.

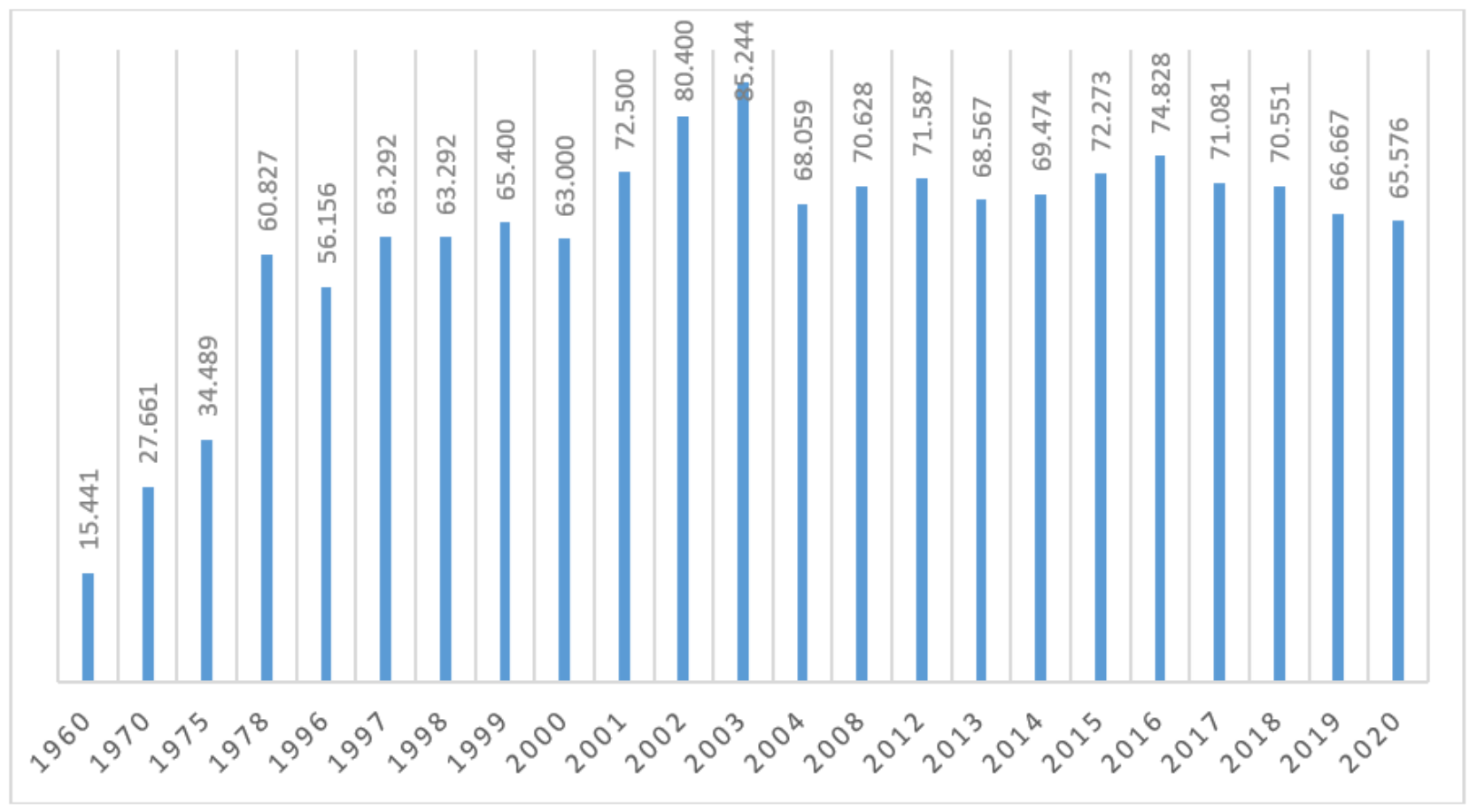

Fuente: elaboración propia en base a censos nacionales agropecuarios, estadísticas provinciales y campañas de vacunación.

El Censo Nacional Agropecuario de 1960 (República Argentina - Dirección Nacional de Estadística y Censos, 1964), relevó la existencia de 15.441 cabezas de ganado vacuno, de las cuales 9.927 cabezas (64\%) correspondía a razas criollas o cuarteronas, iniciandose un proceso cuantitativo en el aumento de los rodeos bovinos, el cual es acompañado con el mejoramientos de los mismos, a partir de la introducción de razas europeas e índicas. Entre 1960 y 1978 se incrementa en 294\% (45.386 cabezas) el número de vacunos, iniciandose un amesetamiento que se prolonga hasta el año 2000, cuando comienza nuevamente un importante incremento que muestra que en el periodo 2000/03 aumentan 22.244 animales (35\%), disminuyendo en 2020 a 65.576 animales, lo que expresa una caida de 19.668 cabezas (-23\%), probablemente traccionada por una seguidilla de años secos iniciados en 2002, pero que igualmente se ubica por encima del promedio histórico de 63.246 vacunos para el periodo considerado en este estudio.

La distribución de existencias bovinas por categoría y su evolución en el periodo 2012/20 puede verse en la Tabla 7, donde llama la atención el incremento en la cantidad de bueyes, ya que en las tareas agrícolas que realizaban los pequeños productores, estos preferían yeguarizos o mulares. Y a partir de 2010, con la sanción de la ley 6.547 que créa en la provincia del Chaco el Régimen de Consorcios Productivos de Servicios Rurales, las tareas de preparación de suelo se mecanizaron.

Tabla 7. distribución de existencias bovinas por categoría y su evolución. Periodo 2012/20.

\begin{tabular}{|c|c|c|c|c|c|c|c|c|c|c|}
\hline Año & Vacas & Vaquillonas & Novillos & Novillitos & Terneros & Terneras & Toros & Toritos & Bueyes & Total \\
\hline 2012 & 35.860 & 7.022 & 2.008 & 4.268 & 10.818 & 9.860 & 1.742 & 9 & 0 & 71.587 \\
\hline 2013 & 34.826 & 6.511 & 1.714 & 4.040 & 10.146 & 9.413 & 1.887 & 3 & 27 & 68.567 \\
\hline 2014 & 36.589 & 6.117 & 1.553 & 3.685 & 9.809 & 9.762 & 1.922 & 13 & 24 & 69.474 \\
\hline 2015 & 37.954 & 6.855 & 1.175 & 3.135 & 10.347 & 10.820 & 1.831 & 3 & 153 & 72.273 \\
\hline 2016 & 39.359 & 7.048 & 1.113 & 3.076 & 11.055 & 11.194 & 1.783 & 12 & 188 & 74.828 \\
\hline 2017 & 38.592 & 6.243 & 1.030 & 2.677 & 10.361 & 10.130 & 1.916 & 1 & 131 & 71.081 \\
\hline 2018 & 38.237 & 5.590 & 910 & 2.317 & 10.857 & 10.541 & 1.768 & 4 & 327 & 70.551 \\
\hline 2019 & 36.267 & 5.361 & 611 & 2.325 & 10.258 & 9.899 & 1.582 & 321 & 43 & 66.667 \\
\hline
\end{tabular}

Fuente: República Argentina - MAGyP (2020).

En la localidad cabecera se encuentra un frigorifico que faena anualmente 15.000 animales, aproximadamente. 


\subsubsection{Forestal}

De las 154.500 hectáreas de superficie departamental con que cuenta Quitilipi, la superficie forestal es de 36.645 hectáreas, representando el $23,7 \%$ de la superficie del departamento y el 0,7\% de la superficie forestal de la provincia.

La región quitilipense fue una de las que sufrió una intensa explotación forestal durante la primera mitad del siglo XX por parte de las empresas productoras de tanino; a lo largo de su historia, como en el resto del Chaco, hubo sectores que extrajeron maderas del bosque nativo destinadas al uso doméstico, producción de leña, carbón, postes, varillas, sumados a las demandas de carpinterías y aserraderos artesanales. En el informe realizado por José Elías Niklinson (1915), dentro de los obrajes de la Tercera Zona, se menciona que al sur de los kilómetros 152/148 del Ferrocarril Central Norte Argentino, se encuentra en actividad el obraje de la Colonia Indígena Napalpí; la población indígena de éste gran obraje no era fija, pero se calculaba en mil personas ${ }^{6}$.

A partir de 1980 resurgió la actividad forestal, pero la modalidad de explotación, esta vez, no fue por medio de grandes empresas sino a través de pequeños y, en menor medida, medianos establecimientos de aserraje y carpintería en la región centro-oriental de la provincia, liderado por la ciudad de Machagai, que en pocos años concentró una gran cantidad de instalaciones que abastecía la demanda, no sólo regional, sino nacional; a esta nueva actividad se sumó Quitilipi, orientándose a la producción de aberturas (Cuadra D. E., 2012), contando con 177 establecimientos foresto-industriales en el año 2019.

\section{Conclusiones}

La configuración histórico-productiva que se dio en el departamento fue el resultado de situaciones políticas, económicas, sociales, biológicas y climáticas que se han dado a lo largo de un siglo en el departamento analizado, debiendo todos estos factores ser analizados en conjuntos para no llegar a conclusiones erróneas. En el periodo analizado puede observarse como luego de una primera etapa de explotación forestal, que acompañó la ocupación militar de la región, el cultivo de algodón condujo la formación y consolidación de colonias, donde la primera industrialización del textil (proceso de desmote) fortaleció el crecimiento de la ciudad cabecera departamental, donde llegaron a instalarse nueve desmotadoras. La primera gran crisis de este cultivo provocó, por un lado, la diversificación agrícola, aumentando la superficie cultivada de otros rubros, incrementando, por otra parte, el número de cabezas de ganado vacuno, como una nueva alternativa productiva, a la vez que se buscaba mejorar la calidad de los rodeos, con la introducción de razas europeas, índicas y sus cruzas; este proceso de reconversión, que permitió a productores medianos y grandes mantenerse en el rubro productivo, provocó el éxodo de pequeños productores, cuyos predios eran insuficientes en superficie para reconvertirse hacia la ganadería, siendo también insuficientes para introducir nuevos cultivos, a la vez que no contaban con capital suficiente como para implementar rubros agrícolas que exigían mayor mecanización.

La concurrencia de grandes inundaciones y bajos precios algodoneros ocurrida en la década del '80 llevó a revalorizar el monte nativo, iniciando un proceso de industrialización de la madera de algarrobo a través de pequeños aserraderos y carpinterías ubicados en la ciudad cabecera, que forjó nuevos emprendimientos generadores de mano de obra que, aunque no frenaron el éxodo rural, contribuyeron a que los expulsados del campo pudieran lograr un trabajo y asentarse en la ciudad de Quitilipi.

Nuevamente inundaciones y fuertes sequías, amén del proceso de tecnificación y bajos precios en el cultivo de algodón que se vivieron alrededor del periodo finisecular, junto a la aparición de una nueva plaga del algodón, el picudo, volvieron a incentivar la actividad ganadera a la vez que el cultivo de soja aparece como una alternativa productiva para los productores de mayor escala, en tanto se revaloriza la producción hortícola y granjera para su venta en los mercados locales para los pequeños productores, que encuentran en la venta a través de la feria franca, puerta a puerta y en comercios minoristas, una alternativa a un algodón que cada vez requería mayor superficie y mayor capital para su cultivo.

\section{Agradecimientos}

A las familias de los productores agropecuarios del departamento Quitilipi, quienes abrieron las tranqueras de sus chacras y las puertas de sus casas, relatando sus experiencias de vida que permitieron comprender los procesos vividos en las áreas rurales de Quitilipi.

A las licenciadas Claudia Landi y Marta Acuña, de la Dirección Nacional de Difusión y Comunicación

$6 \quad$ De los 80 obrajes relevados en el Chaco, la población total era de 8.425 personas (Niklinson, 1915). 
del INDEC, por su colaboración en la búsqueda de censos nacionales.

A Oscar y Facundo Limito, profesionales de la Delegación Quitilipi del Ministerio de Producción de

la Provincia del Chaco y al personal de la Sociedad Rural de Quitilipi, por la información brindada.

\section{Referencias bibliográficas}

Administración Provincial del Agua - Dirección de Estudios Básicos. (2010). Anuario de precipitaciones provincia del Chaco 1956-2010. Resistencia, Chaco, Argentina. Recuperado el 20 de julio de 2020, de https://www.ecomchaco.com.ar/apa/ANUARIO1956-2010.PDF

Barrado, E. M. (2006). Sociedad Rural “Argentina”. Recuperado el 8 de octubre de 2017, de Zona Económica: http://www.zonaeconomica.com/argentina/sociedadrural

Beck, H. B. (1994). Relaciones entre blancos e indios en los Territorios Nacionales de Chaco y Formosa. 1885-1950. Cuadernos de Geohistoria Regional, (29).

CEPRODER. (2006). Propuesta de lineamientos de estrategias para el desarrollo rural de los tres municipios relevados: Quitilipi. Mimeo, República Argentina - Ministerio de Economía y Producción - Secretaria de Agricultura, Ganadería, Pesca y Alimentos, Proyecto de desarrollo de pequeños productores agropecuarios, Resistencia.

Chayanov, A. V. ((1925) 1985). La organización de la unidad económica campesina. Buenos Aires, Argentina: Nueva Visión.

Codutti, R. O. (2003). Diagnostico Agrario y Rural de la Provincia del Chaco. Ministerio de la Producción. Gobierno del Chaco - Fortalecimiento Institucional. Proyecto de Desarrollo de Pequeños Productores Agropecuarios. SAGPyA. (En soporte magnético).

Cuadra, D. E. (2012). La problemática forestal en la provincia del Chaco, Argentina. Un análisis desde la geografía. Revista Geográfica Digital, 9(18). ISSN 1668-5180 Resistencia, Chaco. Recuperado de: https://revistas.unne.edu.ar/index.php/geo/article/view/2232/1954

Cuadra, D. E., Bonfanti, F. A., Andrada, R. F., Golemba, F. E., \& Vera, F. D. (2015). Cambios en las actividades agropecuarias y forestales de la provincia del Chaco (Argentina) y sus efectos sobre la población rural. (I. F. UNNE, Ed.) Revista Geográfica Digital, 12(23), 29.

Dellamea, S. G., \& Cuadra, D. E. (2015). Machagai y colonias vecinas. Geografía, historia, política, economía, sociedad y cultura del Departamento 25 de Mayo, en la Provincia del Chaco. Resistencia, Chaco, Argentina: ConTexto.

INDEC. (2021). Censo Nacional Agropecuario 2018. Resultados definitivos. Ciudad Autónoma de Buenos Aires, Argentina.

Limito, F. (20 de julio de 2020). Entrevista personal. (G. R. Martínez, Entrevistador) Quitilipi, Chaco, Argentina.

Mari, O.E.(2001). Causas de riesgo en una sociedad en formación. La "fiebre del algodón” y sus consecuencias en una jurisdicción argentina. Revista de Geografía Norte Grande (28), 143-155.

Mari, O. E. (July/Sept. de 2016). La coexistencia en la diversidad: Los conjuntos sociales del Chaco argentino durante la primera mitad del siglo 20, y sus formas de vinculación. Civitas - Revista de Ciências Sociais, 16(3), 522-539. doi: https://doi.org/10.15448/1984-7289.2016.3.23762

Martínez, G. R. (2018). La dinámica socio-territorial en el centro-este chaqueño desde finales del siglo XIX hasta principios del siglo XXI. Recuperado el 25 de octubre de 2018, de INTA: https://inta.gob.ar/ documentos/la-dinamica-socio-territorial-en-el-centro-este-chaqueno-desde-finales-del-sigloxix-hasta-principios-del-siglo-xxi

Martínez, G. R., \& Cuadra, D. E. (22 de febrero de 2021). Evolución del sector agropecuario en la provincia del Chaco entre 2002 y 2018. Realidad Económica, 51(337), 115-147.

Miranda, G. A. (1955). Tres ciclos chaqueños (Crónica histórica regional). Santa Fe, Santa Fe, Argentina: Norte Argentino.

Morello, J., \& Adamoli, J. (1970). Las Grandes Unidades de Vegetación y Ambiente del Chaco Argentino. Chaco, Argentina: INTA.

Niklinson, J. E. (1915). Informe del Inspector Niklinson. Boletín, Ministerio de Trabajo, Departamento Nacional 
del Trabajo, Buenos Aires.

OEA. (1977). Cuenca del Plata - Estudio para su Planificación y Desarrollo - República Argentina - Cuenca del Río Bermejo II - Cuenca Inferior. Recuperado el 19 de Febrero de 2014, Recuperado de: http://www. oas.org/usde/publications/Unit/oea22s/begin.htm\#Contents

República Argentina - Congreso Nacional. (876). Ley Nº 817 de Inmigración y Colonización. Buenos Aires, Argentina.

República Argentina - Dirección Nacional de Estadística y Censos. (1964). Censo Nacional Agropecuario 1960 (Vol. II). Buenos Aires, Argentina: Secretaría de Estado de Hacienda.

República Argentina - INDEC. (2008). Censo Nacional Agropecuario 2008. Recuperado de INDEC: http:// www.indec.gob.ar/nivel4_default.asp?id_tema_1=3\&id_tema_2=8\&id_tema_3=87

República Argentina - Instituto Geográfico Nacional. (2016). Mapa de la provincia del Chaco y sus departamentos. Recuperado de Gifex.com: https://www.gifex.com/America-del-Sur/Argentina/ Chaco/index.html

República Argentina - MAGyP. (2020). MAGyP. Recuperado el 30 de diciembre de 2020, de Stock bovino por departamento y estratificación. Series de stock bovino". Años 2007-2019: Recuperado de: https:// www.magyp.gob.ar/sitio/areas/bovinos/informacion_interes/informes/index.php

República Argentina - MAGyP. (2020). SIIA. Recuperado de: Sistema Integrado de Información Agropecuaria: http://www.siia.gov.ar/

Schaller, E. C. (1986). La colonización en el territorio nacional del Chaco en el período 1869 - 1921 (Vol. Cuaderno de Geohistoria Regional № 12). Resistencia, Chaco, Argentina: IIGHI CONICET. 